\title{
The biological false positive reaction to serological tests for syphilis
}

\author{
M. F. GARNER
}

From the Institute of Clinical Pathology and Medical Research, Lidcombe, Sydney, Australia

SYNOPSIS Acute and chronic biological false positive reactions to serological tests for syphilis are discussed. Three cases are presented, one showing an acute and one a chronic reaction, and one in which it was not possible to determine if the reaction was acute or chronic. Once a biological false positive reaction is found, serum from the patient should be tested at intervals for at least six months to determine if the reaction is acute or chronic. If a chronic reaction is found the patient should then be investigated to find the underlying cause.

Problem sera from 753 patients are reviewed. Biological false positive reactions were shown by 47 sera and 257 sera gave results indicating they came from patients infected with syphilis. The reactive sera were divided into four groups: sera from blood donors, antenatal patients, cases of recent vaccination, and a miscellaneous group. It was found that in the first three groups the number of sera from patients showing biological false positive reactions was equalled or exceeded by the number showing syphilitic reactions.

Biological false positive reactions in sera from cases of lepromatous leprosy and in sera from the inhabitants of the Okapa region of New Guinea are also discussed.

It is concluded that sera which give reactive results to reagin detection tests for syphilis? and come from patients known to have conditions which cause acute or chronic biological false positive reactions should never be dismissed as such. Experience has shown that a number of these sera will give reactive Treponema pallidum immobilization test results, that is, they come from patients who have or have had syphilis.

\begin{abstract}
A biological false positive reaction may be defined as a positive reaction to reagin tests, and a negative reaction to treponemal tests, in the serum of a patient who has no history or clinical evidence of syphilis or other treponematosis (King, 1964). The treponemal diseases such as yaws and pinta, caused by organisms closely related to $T$. pallidum, give reactive results to both Received for publication 23 April 1969.
\end{abstract}

reagin and treponemal tests, and so do not give biological false positive reactions. A typicalo biological false positive result on a serum will $\stackrel{\circ}{\circ}$ therefore give a positive reaction to the cardi- $\vec{\Phi}$ olipin Wassermann reaction (CWR) and/or Venereal Disease Research Laboratory (VDRL) test, and negative reactions to the Reiter protein 8 complement-fixation (RPCF), Treponema palli dum immobilization (TPI), and fluorescentoㅡㅡㄹ 
treponemal antibody absorption tests. The TPI test is the test of choice to confirm a biological false positive result. The fluorescent treponemal antibody absorption test is not as specific as the TPI test and therefore not as well fitted for the demonstration of biological false positive sera (Fribourg-Blanc and Niel, 1967). Recent work by Kiraly, Jobbagy, and Kovats (1967) has shown that the absorbing agent used in the fluorescent treponemal antibody absorption test does not in every case remove all non-specific factors from the serum being tested so it is possible with a few sera to obtain a false reactive result to this test. The antibody reagin, detected by the CWR and VDRL tests, is present in minute amounts in the serum of all normal human beings. Certain events can cause this amount to undergo a marked increase, infection with syphilis being the most consistent in effect (King, 1964).

The biological false positive reaction is not simply related to increased globulin in the serum, as many diseases with increased serum globulin do not give these reactions; neither do all patients with diseases known to cause these reactions show them nor does the increase in globulin have any relationship to the reagin titre (King, 1964).

There are two types of biological false positive reactions, acute and chronic.

\section{Acute Reactions}

Acute biological false positive reactions usually develop during or shortly after an acute infection. These reactions last for a few days to a few weeks, or at the most six months after the patient's recovery from the cause of the reaction, when they disappear spontaneously (King, 1964). The reagin test results are usually weakly reactive, with low titres, and there are frequently discrepancies between the results of individual tests (Garner, 1966). Examination of the cerebrospinal fluid is not necessary.

\section{ILLUSTRATIVE CASE 1}

Serum was received from C.D., a 23-year-old woman (Table I), who gave a history of having been recently vaccinated against smallpox. The test results on 14 February 1960, together with the history and the discrepancy, though not marked in CWR and VDRL test titres, suggested a

\begin{tabular}{|c|c|c|c|c|c|c|}
\hline \multirow{2}{*}{$\begin{array}{l}\text { Date } \\
\text { of } \\
\text { Serum }\end{array}$} & \multirow[t]{2}{*}{ History } & \multicolumn{5}{|c|}{ Test Results ${ }^{1}$} \\
\hline & & $C W R$ & $V D R L$ & $R P C F$ & $T P I$ & $F T A-A B S$ \\
\hline $\begin{array}{r}14-2-66 \\
8-3-66\end{array}$ & Recent vaccination & $\begin{array}{l}\mathbf{R T}=5 \\
\mathbf{N R}\end{array}$ & $\begin{array}{l}\text { R1:4 } \\
\text { R1:2 }\end{array}$ & $\begin{array}{l}\text { NR } \\
\text { NT }\end{array}$ & $\begin{array}{l}\text { NR } \\
\text { NR }\end{array}$ & $\begin{array}{l}\text { NR } \\
\text { NR }\end{array}$ \\
\hline
\end{tabular}

Table I Results of tests in case 1

${ }^{1} \mathbf{R}=$ reactive (positive)

$\mathbf{N R}=$ Non-reactive (negative) biological false positive reaction; the nor o reactive fluorescent treponemal antibody absorp tion test result made a diagnosis of primary syphilis unlikely. A second specimen of serun received three weeks later, in which the reagif test results were fading, confirmed the biologica: false positive reaction.

$\stackrel{\infty}{+}$

Recognized causes of acute biological fals, positive reactions are pregnancy, upper respi atory tract infections, measles, chickenpox infective hepatitis, virus pneumonia, and malariæ, and also following vaccination and immunizatiofis (King, 1964). Moore and Mohr in 1952 listed as less common causes of the acute reaction lymphogranuloma venereum, chancroid, tube $\overrightarrow{\mathrm{E}_{0}}$ culosis, pneumococcal pneumonia, and lepto? spirosis. Narcotic addiction was shown bf Harris, Brown, Portnoy, and Price (1962) to be another cause of the acute reaction.

\section{Chronic Reactions}

Chronic biological false positive reactions a characterized by the persistence of reactive reagin tests for a period exceeding six months and by the absence of those disorders known tol cause the acute reaction (King, 1964). Chronjc reactions may last for years or even for life. The titres in the reagin tests are usually low, but may be high, and, as in the acute reaction, dig crepancies are not unusual between the results of the individual reagin tests (Garner, 1966). Aq examination of the cerebrospinal fluid is desirabl $\overrightarrow{\vec{B}}$

illuSTRATIVE CASE 2

Serum was tested from P.C., a 65-year-ot woman (Table II). The history stated that she had had a positive Wassermann reaction 30 yea before. She gave no history to support this and showed no clinical signs of infection. The test results fulfilled all the criteria of a chronic biological false positive reaction, ie, reactive reagin tests for over six months with no reactive treponemal tests, no history or clinic ầ signs of syphilis, low titre CWR results, ard discrepancies, though not marked, in reagin tast titres.

Patients with chronic biological false positife reactions can be divided into several groups: (1) those with no clinical evidence of illne regarding themselves as being in perfect healt $\mathbb{R}_{\text {; }}$; (2) those suffering from a condition known to cause a chronic reaction; and (3) those who suffir from episodes of arthralgia, arthritis, fever, and malaise.

Conditions associated with the chronic bialogical false positive reaction are leprosy (Nelsoin, 1952); systemic lupus erythematosus, rheumatogd arthritis, rheumatic fever, polyarteritis nodoga (Zellman, 1952); lymphatic leukaemia, perniciots 


\begin{tabular}{|c|c|c|c|c|c|c|}
\hline \multirow{2}{*}{$\begin{array}{l}\text { Date } \\
\text { of } \\
\text { Serum }\end{array}$} & \multirow[t]{2}{*}{ History } & \multicolumn{5}{|c|}{ Test Results ${ }^{1}$} \\
\hline & & $C W R$ & $V D R L$ & $R P C F$ & $T P I$ & $F T A-A B S$ \\
\hline $\begin{array}{l}19-10-66 \\
9-2-67 \\
30-5-67 \\
\text { C.S.F. }\end{array}$ & Positive WR 30 years before & $\begin{array}{l}\mathbf{R T}=2 \cdot 5 \\
\mathbf{R T}=5 \\
\mathbf{R T}=2 \cdot 5\end{array}$ & $\begin{array}{l}\text { R } 1: 2 \\
\text { R } 1: 2 \\
\text { R }\end{array}$ & $\begin{array}{l}\text { NR } \\
\text { NR } \\
\text { NR }\end{array}$ & $\begin{array}{l}\text { NR } \\
\text { NR } \\
\text { NR }\end{array}$ & $\begin{array}{l}\text { NR } \\
\text { NR } \\
\text { NR }\end{array}$ \\
\hline $10-11-66$ & & NR & NR & NR & NR & NR \\
\hline
\end{tabular}

Table II Results in case 2

${ }^{1} \mathbf{R}=$ reactive (positive)

NR = Non-reactive (negative)

anaemia, and metastatic carcinoma (King, 1964). The chronic type of reaction is commoner in females than in males; about $70 \%$ of patients are females (Moore and Lutz, 1955). The chronic biological false positive reaction has been regarded by some as a means of identifying individuals with a basic abnormality of the immune apparatus (Harvey, 1962).

Unless tests are carried out on a patient's serum over a period exceeding six months it is not always possible to be certain if the biological false positive reaction is acute or chronic.

\section{ILLUSTRATIVE CASE 3}

Serum was received from a patient A.B., a 21-year-old woman, for routine antenatal tests for syphilis (Table III). The history stated that she was 10-11 weeks pregnant on 2 December 1965. The results of her tests repeated three weeks later suggested a biological false positive reaction. Again the pattern was typical of this reaction, except for the results of tests on 1 April 1966 which were done five to six weeks after the patient had had a miscarriage. No further serum was received from this patient until 11 months later when the tests showed the usual biological false positive pattern. This came from a maternity hospital with a history of '?biological false positive reaction', so presumably the patient was pregnant again. Serum from the husband $u$ as tested in December 1965 and was found to be non-reactive in all tests, including the TPI test.

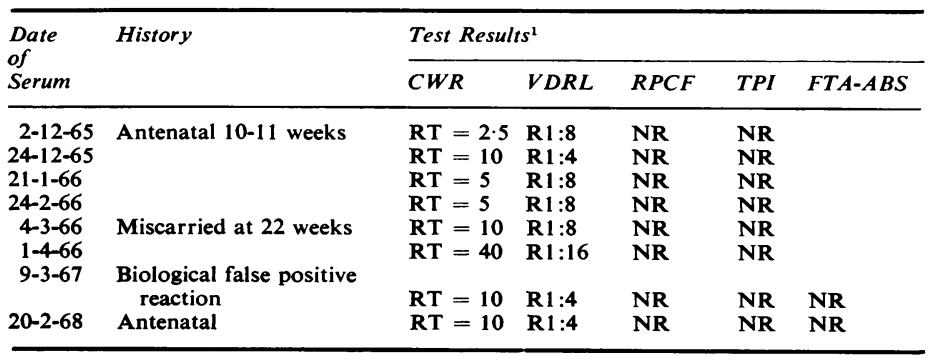

Table III Results in case 3

${ }^{1} \mathbf{R}=$ reactive (positive)

NR $=$ Non-reactive (negative)

\section{Problem Sera}

In the first six months of 1968,753 problem sera were sent to the Institute for TPI testing. Problem sera are those in which other laboratories have 으․ obtained equivocal results to routine tests for $\vec{F}$

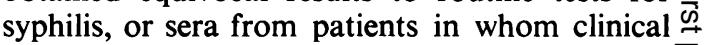
findings, history, and serological test results conflict. Sera from 47 patients gave biological 음 false positive reactions, ie, reactive results to $\vec{D}$ reagin tests and non-reactive results to the TPI $\varnothing$ and fluorescent treponemal antibody absorption $\%$ tests. Results which indicated a diagnosis of $\vec{\circ}$ syphilis were obtained with 257 sera in the group. The 47 sera from biological false $\vec{\omega}$ positive reactors could be divided into four groups: blood donors, antenatal patients, recently vaccinated patients, and a miscellaneous group. N Table IV shows the number of sera in each group $\rightarrow$ which gave biological false positive reactions as well as those which gave results indicating 을 syphilis. No further specimens of serum were received from the 47 patients whose sera showed $T$ biological false positive reactions so it was not $\mathbb{D}$ possible to determine which were acute and which chronic reactors.

\begin{tabular}{lllr}
\hline Group & $\begin{array}{l}\text { No. of } \\
\text { Sera Tested }\end{array}$ & $\begin{array}{l}\text { No. of Sera Showing } \\
\text { Reactions }\end{array}$ \\
\cline { 2 - 4 } & & $\begin{array}{l}\text { Biological False } \\
\text { Positive }\end{array}$ & Syphilis \\
\hline Blood donors & 88 & 22 & 22 \\
Antenatal & 88 & 14 & 17 \\
Vaccination & 15 & 2 & 2 \\
Miscellaneous & 562 & 9 & 216 \\
Total & 753 & 47 & 257 \\
\hline
\end{tabular}

Table IV Biological false positive and syphilitic reactions found on serological testing of 753 problem? sera

\section{Leprosy Sera}

Sera from 270 patients with lepromatous leprosy were obtained from the Philippines. Biological $/$ false positive reactions were found with the sera $N$ from 25 patients and 15 patients had results N indicating that they had a treponemal infection.

\section{New Guinea Sera}

In a group of 1,390 sera tested from the inhabitants of the Okapa district of the Eastern High- $\frac{?}{\mathbb{D}}$ lands of New Guinea, 10 sera showed biological 0 false positive reactions as opposed to 346 sera? showing results which indicated a treponemalo infection (Garner and Hornabrook, 1968; Garnero and Hornabrook, 1969). 


\section{Discussion}

The acute biological false positive reaction illustrated by case 1 shows the type of result seen most frequently in people who show a primary response to vaccination. Lynch, Kimball, and Kernan in 1960 investigated cases of recent smallpox vaccination amongst university students, and found 57 of 212 cases giving biological false positive reactions. Reactivity was maximal 19-22 days after vaccination and persisted for up to 112 days. They used the RPCF test to identify the biological false positive reactions.

If the patient in case 2, which illustrates a chronic biological false positive reaction, had had syphilis 30 years ago and been treated, one would reasonably expect either the TPI or the fluorescent treponemal antibody absorption tests or both to be reactive. In a longstanding case of treated syphilis it is more usual for the RPCF, TPI, and usually the fluorescent antibody absorption tests to be reactive and the CWR and VDRL test non-reactive. Before the introduction of the TPI test the distinction between a chronic biological false positive reaction and latent syphilis in patients with no evidence of disease was a matter of probability, and in many cases antisyphilitic treatment was given to cover the risk of misdiagnosis (King, 1964). This could well have happened in case 2 .

A person whose serum shows a chronic biological false positive reaction may develop a condition known to cause an acute reaction, eg, a chronic reactor can become pregnant. Thus a biological false positive reaction in a pregnant patient cannot be dismissed as an acute reaction unless the patient's serum is tested six months after termination of the pregnancy. It was unlikely that the patient in case 3 was suffering from congenital syphilis, as, if this were the case, discrepancies in the CWR and VDRL titres would not have been so marked, the Reiter protein complement-fixation test would be expected to show a reactive result, and either the TPI or fluorescent treponemal antibody absorption tests would have been reactive. To date, we have not been able to determine if this patient is an acute or a chronic reactor.

The incidence of biological false positive reactions in the problem group tested was $6.2 \%$. This is much higher than in a normal population group as problem sera are heavily loaded in favour of both biological false positive and syphilitic reactions. By contrast, 21,924 sera were submitted to the laboratory in the first six months of 1968 for routine serological tests for syphilis. Only 50 sera $(0 \cdot 23 \%)$ were found to give biological false positive reactions. In the blood donor, antenatal and vaccinated groups, it is of interest that the numbers of biological false positive sera are equalled or exceeded by the numbers of syphilitic sera. This illustrates well the fact that it is extremely unwise to dismis a reactive result to a screening test for syphilis: as a biological false positive reaction, especiallyo when found in the serum of a patient with condition known to cause such a reaction. AP such sera should be submitted for TPI testing Had this not been done in the groups of problenf? sera discussed, 17 congenital syphilitic babie instead of 17 normal healthy babies might have been born.

Biological false positive reactions in bloo $\$$ donors are of interest since, to my knowledge they have not previously been reported. It may be that blood loss stimulates the immune mechanism which, in some individuals, produces excess reagin. Nine of 22 blood donors exhibiting biological false positive reactions had give? many donations (one 20 and another 23) Reactive serological tests in blood donors should be thoroughly investigated to determine theig cause. In our series, of the 44 reactors, 22 wers established as biological false positive reactors and in 22 the reaction was due to syphilis. Th

The lepromatous form of leprosy is we known to give rise to chronic biological falsê positive reactions. Since the TPI test is not usuall performed in those areas which have a high incidence of leprosy, we decided to see if the fluorescent treponemal antibody absorption test compared favourably with the TPI test in detect ing these sera. In our series the former tes though not as specific as the TPI test, compared favourably with it in demonstrating biologicå false positive sera (Garner, Backhouse, Collin\$ and Roeder, 1969).

\section{References}

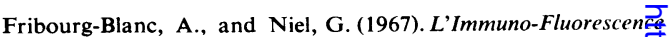
Appliquee $A u$ Diagnostic Serologique de la Syphito (Unpublished working document WHO/VDT/RES 67.11 Garner, M. F. (1966). The serodiagnosis of syphilis. Med. $\frac{\bar{\Phi}}{0}$ Aust., 2, 328-331.

Garner, M. F., Backhouse, J. L., Collins, C. A., and Roeder, P. $\Phi$ (1970). Brit. J. vener. Dis., in press.

Garner, M. F., and Hornabrook, R. W. (1968). Treponematosis the eastern highlands of New Guinea. Bull. Wld Hlth Or. 38, 189-195.

Garner, M. F., and Hornabrook, R. W. (1969). Bull. Wld Hlth Org, in press.

Harris, A., Brown, L., Portnoy, J., and Price, E. V. (1962). Narcots addiction and BFP reactions in tests for syphilis. Pug. Hlth Rep. (Wash.), 77, 537-543.

Harvey, A. M. (1962). Auto-immune disease and the chrorio biological false-positive test for syphilis. J. Amer. met? Ass., 182, 513-518.

King, A. (1964). Recent Advances in Venereology. Churchilp London.

Kiraly, K., Jobbagy, A., and Kovats, L. (1967). Group antibodies in fluorescent treponemal antibody (FTA) test. J. in Derm., 48, 98-100.

Lynch, F. W., Kimball, A. C., and Kernan, P.D. (1960). Serelog்c tests for syphilis following smallpox vaccination a including Reiter protein complement fixation technique.

J. invest. Derm., 34, 219-222.
Moore, J. E., and Mohr, C. F. (1952). Biologically false posit . serologic tests for syphilis. J. Amer. med. Ass., 150, 467-4

Moore, J.E., and Lutz, W. B. (1955). Natural history of systengुc lupus eryt hema tosus: approach to its study through chror biologic false positive reactors. J. chron. Dis., 1, 297-3 6 .

Nelson, R. A. (1952). Changing concepts in the sero-diagnosis syphilis: specific treponemal antibody versus Wassermann reagin. Brit. J. vener. Dis., 28, 160-168.

Zellman, H. E. (1952). The incidence of positive serological tess for syphilis in the collagen diseases. Amer. J. Syph., 通, 163-166. 